\title{
GEOQUÍMICA AMBIENTAL DA SUB-BACIA HIDROGRÁFICA DO RIBEIRÃO DAS PEDRAS, DIAMANTINA, MG.
}

\author{
Soraya de Carvalho Neves ${ }^{1}$, Adolf Heirich Horn², Lucio Mauro Soares Fraga ${ }^{3}$
}

\begin{abstract}
Geochemistry environment of the River of the Stones sub-basin, Diamantina, MG.

The soils, stream sediments and surface water are considered as component of the natural geochemical system inside the hydrographic basin and, therefore, with the geochemistry characterization it is possible to effect an evaluation of the environment chemical quality of the sub-basin of River of the Stones. The draining net of this sub-basin has as bedrock sequences of Supergroup Espinhaço, rocks of Supergroup Paraúna River, beyond associating intrusive igneous rocks. The geomorphology context includes events of deposition and denudation of the uplands, however preserved in the top of the watersheds. This sub-basin was selected for studies due to its characteristics of urban occupation and for the fact of getting into a unit of conservation. The regional geochemical data had been used as comparative base for the results of the analyses in the sub-basin. The physical-chemical analyses of soils, stream sediment and water had been carried through in periods of dry and rainy seasons. The results had been dealt statistically and compared with values standards defined for the environmental legislation. It was established through analyses a natural standard relatively high for the iron and aluminum. In the sample of superficial waters and stream sediments it had been detected prompt contaminations of cadmium, plumb and mercury that can be related, in general, to mining activities or the urban expansion. In the soil it was found natural concentrations of arsenic, zinc, cupper and barium related with the rock's composition in the region.
\end{abstract}

Key words: water, soils, heavy metals.

\section{RESUMO}

\begin{abstract}
Os solos, sedimentos de corrente e águas superficiais são considerados como componentes do sistema geoquímico natural dentro da bacia hidrográfica e, portanto, com a caracterização geoquímica é possível efetuar uma avaliação da qualidade química ambiental da sub-bacia do Ribeirão das Pedras. A rede de drenagem dessa sub-bacia tem como substrato rochoso seqüências do Supergrupo Espinhaço, rochas do Supergrupo Rio Paraúna, além de intrusões metaígneas associadas. O contexto geomorfológico inclui eventos de deposição e denudação das superfícies de aplainamento, ora preservados no topo dos divisores de águas. Esta sub-bacia foi selecionada para estudos devido às suas características de ocupação urbana e pelo fato de adentrar em uma unidade de conservação. Os dados geoquímicos regionais foram utilizados como base comparativa para os resultados das análises na sub-bacia. As análises físico-químicas de solos, sedimentos de corrente e água foram realizadas em períodos das estações seca e chuvosa. Os resultados foram tratados estatisticamente e comparados com valores padrões definidos pela legislação ambiental. Estabeleceu-se através das análises um padrão natural relativamente alto para o ferro e alumínio. Nas amostras de águas superficiais e sedimentos de corrente foram detectadas contaminações pontuais de cádmio, chumbo e mercúrio, que podem ser relacionadas, em geral, à atividade garimpeira ou à expansão urbana. Nos solos foram encontradas concentrações naturais de arsênio, zinco, cobre e bário relacionados à composição das rochas aflorantes na região.
\end{abstract}

Palavras-chave: água, solos, metais pesados.

\section{INTRODUÇÃO E OBJETIVO}

A Serra do Espinhaço representa o berço das águas das bacias dos rios Jequitinhonha, São Francisco e Doce. A sub-bacia hidrográfica do Ribeirão das Pedras (Figura 1) pertence à bacia do Rio Jequitinhonha, que nasce no alto desta serra e segue para o Oceano Atlântico através da região nordeste do Estado de Minas Gerais e sul da Bahia.

Foram realizadas diversas análises geoquímicas em solos, águas e sedimentos de corrente, com o objetivo de avaliar a qualidade química ambiental da sub-bacia. Essa sub-bacia mostra uma importância particular por constituir a fonte de captação de água para o abastecimento da cidade de Diamantina (APA Pau de Fruta - COPASA, na parte superior desta sub- bacia). Após alimentar a represa de captação de água, o curso principal atravessa dois clubes campestres e incluindo que sua rede de drenagem no médio curso atravessa por toda a extensão do Parque Estadual do Biribiri, indo desaguar no Rio Pinheiro próximo à localidade homônima. No entanto, algumas das nascentes encontram-se nas imediações das sedes dos distritos de Sopa e Guinda, que despejam seus esgotos e outros dejetos em cursos d'água do sistema, além de recolher produtos das áreas degradadas pelo garimpo de diamantes.

A partir do cruzamento do mapa geológico com mapas pedológicos e hidrográficos da bacia, juntamente com análises químicas dos solos e águas em períodos diferenciados (seca e chuva), foi possível determinar

\footnotetext{
1 - Faculdade de Ciências Biológica e Saúde; Depto. de Ciências Biológicas; UFVJM. soraneves@yahoo.com.br 2 - Instituto de Geociências, Depto.de Geologia, UFMG. hahorn@ufmg.br
}

3 - Faculdade de Ciências Agrárias, Depto. de Engenharia Florestal, UFVJM. luciofraga@yahoo.com.br 
a composição natural das águas superficiais e solos da região e avaliar a qualidade química ambiental dessa sub-bacia. Essa avaliação possibilitou o estabelecimento de valores padrões de qualidade das águas e de contaminação dos solos para as microbacias do Alto Jequitinhonha.

\section{METODOLOGIA}

Inicialmente foram realizados trabalhos de campo com levantamentos geológicos, pedológicos, incluindo a coleta de amostras de água bruta, de diferentes tipos e níveis de solos e sedimentos de corrente. O plano de amostragem considerou os critérios de áreas de nascentes, influência geológica e proximidade de interferência antrópica: garimpos, área urbana, áreas agropastoris, balneários. As amostras foram enviadas ao laboratório Likefield Geosol S/A para determinação de metais pesados. Os demais parâmetros foram avaliados in locu ou no laboratório regional da COPASA, em Diamantina. Nas análises de água, foram considerados os diversos parâmetros físico-químicos: $\mathrm{pH}$, temperatura, turbidez, cor, condutividade elétrica, fósforo, nitrogênio e a concentração de metais pesados totais e dissolvidos (Cu, Zn, Pb, Mn, Fe, Al, Cr, Hg, Cd). Para avaliação da qualidade da água, os resultados foram comparados com os valores padrões da DN 010/86 -COPAM/MG, Resoluções 020/86 e 357/05-CONAMA e Portaria N 1469 do Ministério da Saúde. As análises dos solos foram submetidas à espectroscopia de emissão atômica (ICP-plasma), para determinação de 33 elementos químicos. Para avaliação dos solos foram feitos perfis de classificação pedológica e levantamento de atributos diagnósticos: análise granulométrica, matéria orgânica, soma de bases, capacidade de troca catiônica (CTC), saturação em alumínio e por bases; as análises foram realizadas no laboratório de solos da Faculdade de Ciências Agrárias da UFVJM. As médias obtidas foram comparadas e para avaliação da sazonalidade aplicouse método estatístico não-paramétrico de Wilcoxon. Os resultados obtidos foram integrados em Sistema de Informações Geográficas (SIG).

\section{FISIOGRAFIA}

O substrato da bacia do Ribeirão das Pedras é constituído, principalmente, por seqüências metassedimentares do Supergrupo Espinhaço ( $\mathrm{SgE}$ ) e subordinadamente por rochas do Supergrupo Rio Paraúna (SgRP) e diques de rochas metabásicas. As litologias podem ser agrupadas em quartzitos puros, impuros e/ou ferruginosos, filitos e filitos hematíticos das formações pertencentes ao grupo Guinda (São João da Chapada, Sopa-Brumadinho e Galho do Miguel - SgE); quartzitos ferruginosos e quarzto-sericita xistos das formações Bandeirinha e Barão do Guaicuí (Grupo Costa Sena - SgRP) e rochas ígneas alteradas de composição básica alojadas em diques orientados a SW-NE (Almeida-Abreu, 1993). A sobreposição do sistema hidrográfico deu-se preferencialmente, ao longo das descontinuidades geológicas, definindo, um padrão estrutural de drenagem de configuração subretangular a sub-linear. A bacia está inserida em três compartimentos geomorfológicos: o bloco sul/sudoeste (região de Guinda/Sopa e APA-Pau de Fruta); o segundo compartimento corresponde à região central da bacia (bloco rebaixado), cuja estruturação principal é uma falha de empurrão de direção N-S, com falhas transcorrentes ( EW) associadas; o bloco norte é limitado por falha normal de direção NW-SE, que produz o soerguimento de rochas da base do grupo Guinda, na área do Parque do Biribiri. De maneira geral, durante as fases de dissecação do relevo, desde o período cretáceo até tempos recentes, o comportamento dos elementos hidrográficos nortearam o processo de configuração da atual paisagem da bacia.

\section{HIDROQUÍMICA}

A partir da análise do balanço hídrico para a região de Diamantina (dados da Estação $8^{\circ}$ Distrito INMET-Diamantina), estabeleceu-se a variação da sazonalidade entre um período seco (abril a outubro) e outro chuvoso (novembro a março). Os pontos de coleta mais importantes foram selecionados para monitoramento periódico dos parâmetros de qualidade das águas, conforme indicado na figura 2. De maneira geral, observou-se que as corredeiras e quedas d'água do ribeirão proporcionam boas condições de oxigenação e depuração dos efluentes nele despejados. Há um predomínio da coloração escura $(\sim 100 \mathrm{UH})$ devido, principalmente, à concentração de matéria orgânica dissolvida (oriunda de pequenos brejos nas cabeceiras ou planície aluvial das drenagens) e ao alto teor em ferro nas águas. A temperatura da água mostrou uma variação sazonal média de $3^{\circ} \mathrm{C}$. $\mathrm{O} \mathrm{pH}$ médio para a bacia é ácido, chegando até 4 em períodos chuvosos. Essa característica é devido ao elevado teor de ácidos húmicos, que também influencia na coloração e no conteúdo de nitrogênio orgânico. A condutividade elétrica atinge valores mais altos em pontos de despejo de esgoto doméstico, proporcional ao aumento na concentração de nitrogênio amoniacal. $\mathrm{O}$ nitrogênio orgânico, em geral, aumenta em áreas onde as nascentes estão localizadas em solos hidromórficos e/ou com turfeiras. A concentração de fósforo nas águas da região é relativamente alta, sendo a média acima do limite estipulado pela legislação vigente. Os valores de turbidez estão diretamente relacionados às atividades de exploração mineral (garimpos de diamantes, extração de areia) nos cursos e subordinadamente às enxurradas no período chuvoso.

As análises de metais mostraram um padrão natural elevado para os elementos ferro e alumínio. O ferro total nas águas fluviais mostra concentrações bem acima dos limites estipulados pela DN 010/86 


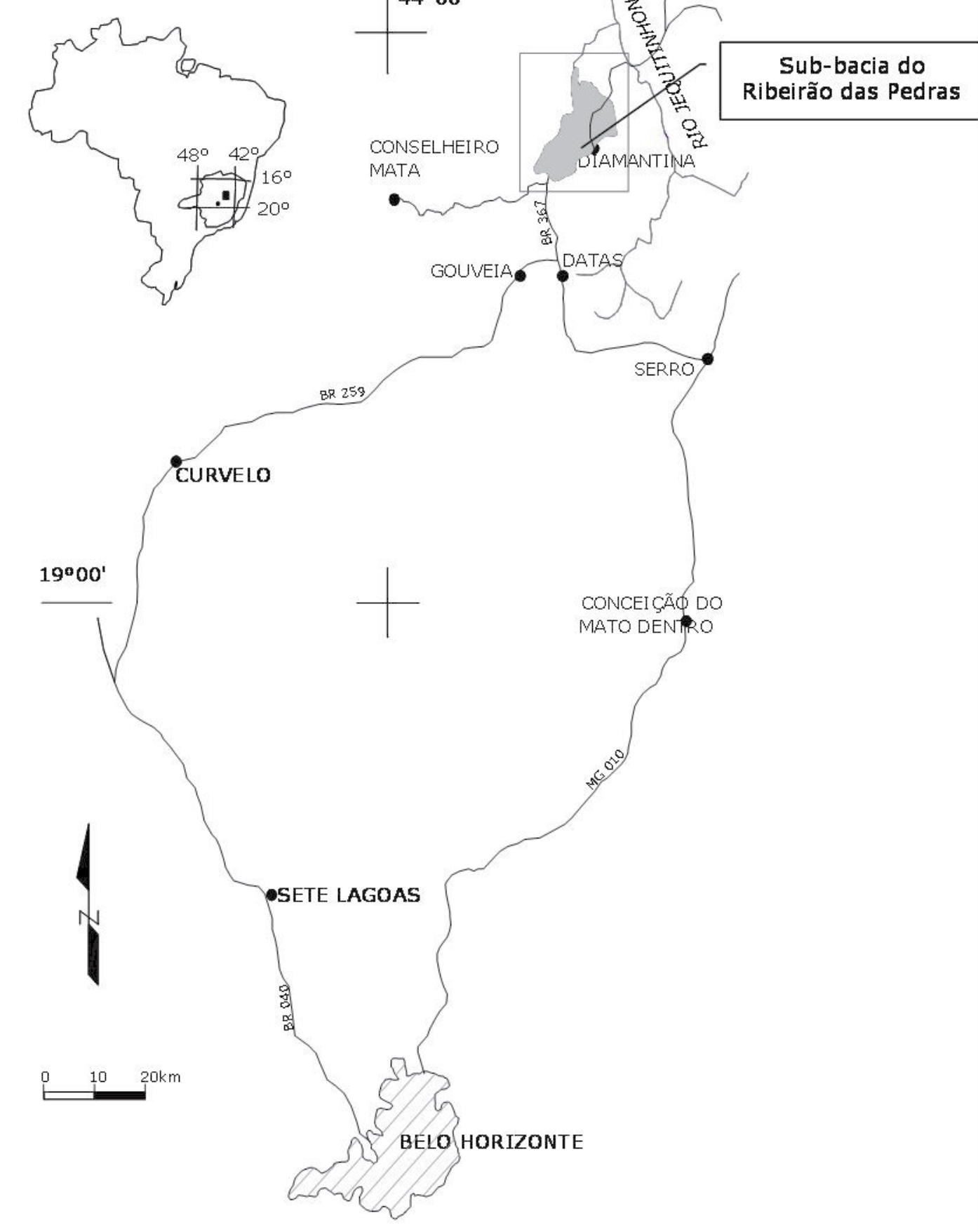

Figura 1: Mapas de localização e vias de acessos a sub-bacia hidrográfica do Ribeirão das Pedras (modificado de Neves, 2005).

para classes I, II e III. No geral, desconsiderando-se os valores extremos, o valor modal é de $1,22 \mathrm{mg} / \mathrm{L}$. O alumínio apresentou média geral de concentração alta para o período chuvoso. Valores extremos são observados pontualmente, como por exemplo, no Ribeirão do Guinda com 15,70mg/L. Em conseqüência, principalmente, da atividade garimpeira no leito e nas margens desse curso. Constatou-se que as concentrações de ferro e alumínio no período chuvoso são muito superiores às concentrações no período seco, mostrando uma relação direta com turbidez provocada por erosão durante enxurradas. Na região de Guinda, foram detectadas concentrações anômalas de cádmio, chumbo, mercúrio. A principal fonte de cádmio e chumbo no caso são os resíduos devido à deterioração de equipamentos de mineração, baterias e combustíveis. O mercúrio encontrado é devido à utilização deste elemento no processo de concentração do ouro (produto secundário). Além destes outros metais provindos das atividades garimpeiras também foram encontrados: zinco, cobre e cromo (ver tabela 1). Algumas contaminações por agentes bacteriológicos foram identificadas no córrego 


\begin{tabular}{|c|c|c|c|}
\hline \multirow[b]{2}{*}{ PARÂMETROS } & \multicolumn{2}{|c|}{ VALOR MÉDIO } & \multirow[b]{2}{*}{ VALORES MÁXIMOS } \\
\hline & $\begin{array}{l}\text { Período } \\
\text { chuvoso }\end{array}$ & Período seco & \\
\hline Temperatura & $22,6^{\circ} \mathrm{C}$ & $19,4^{\circ} \mathrm{C}$ & \\
\hline Cor & $109,2 \mathrm{UH}$ & & $140 \mathrm{UH}$ \\
\hline Turbidez & $7,7 \mathrm{NTU}$ & & 80NTU \\
\hline $\mathrm{pH}$ & 5,2 & & \\
\hline DBO & $<2 \mathrm{mg} / \mathrm{L} \mathrm{O} \mathrm{O}_{2}$ & & \\
\hline OD & $6,9 \mathrm{mg} / \mathrm{L} \mathrm{O}_{2}$ & & \\
\hline $\begin{array}{l}\text { Condutividade } \\
\text { Elétrica }\end{array}$ & $16,18 \mu \mathrm{s} / \mathrm{cm}$ & $7,90 \mu \mathrm{s} / \mathrm{cm}$ & \\
\hline $\begin{array}{l}\text { Nitrogênio } \\
\text { Amoniacal }\end{array}$ & $0,15 \mathrm{mg} / \mathrm{L} \mathrm{N}$ & & $2,66 \mathrm{mg} / \mathrm{L} \mathrm{N}$ \\
\hline $\begin{array}{l}\text { Nitrogênio } \\
\text { Orgânico }\end{array}$ & $0,03 \mathrm{mg} / \mathrm{L} \mathrm{N}$ & & \\
\hline Fósforo & $0,06 \mathrm{mg} / \mathrm{L} \mathrm{P}$ & & $0,23 \mathrm{mg} / \mathrm{L} \mathrm{P}$ \\
\hline \multirow[t]{2}{*}{ Metais } & $\mathrm{Fe}-1,23 \mathrm{mg} / \mathrm{L}$ & $0,44 \mathrm{mg} / \mathrm{L}$ & $\begin{array}{l}\mathrm{Fe}-15,70 \mathrm{mg} / \mathrm{L} ; \mathrm{Zn}- \\
0,01 \mathrm{mg} / \mathrm{L} ;\end{array}$ \\
\hline & $\mathrm{Al}-1,52 \mathrm{mg} / \mathrm{L}$ & $0,16 \mathrm{mg} / \mathrm{L}$ & $\begin{array}{l}\mathrm{Al}-19,60 \mathrm{mg} / \mathrm{L} ; \quad \mathrm{Pb}- \\
0,08 \mathrm{mg} / \mathrm{L} ;\end{array}$ \\
\hline Bacteriológico & $\begin{array}{l}\text { Coliformes } \\
\text { Totais }\end{array}$ & $\begin{array}{l}\text { Coliformes } \\
\text { Fecais }\end{array}$ & $\begin{array}{l}\mathrm{Hg}-0,0003 \mathrm{mg} / \mathrm{L} ; \mathrm{Cd}- \\
0,009 \mathrm{mg} / \mathrm{L} ; \\
\text { Cu-0,01mg/L; Cr-0,05mg/L }\end{array}$ \\
\hline \multicolumn{2}{|c|}{$\begin{array}{l}510- \\
40.000 U F C / 100 \mathrm{ml}\end{array}$} & \multicolumn{2}{|c|}{$\begin{array}{l}110- \\
23.000 U F C / 100 \mathrm{ml}\end{array}$} \\
\hline
\end{tabular}

Tabela 1 - Valores médios e máximos obtidos para os parâmetros físico-químicos e metais, em águas superficiais da sub-bacia do Ribeirão das Pedras.

Tijuco e na cachoeira da Toca (balneário), relacionada ao lançamento de esgoto doméstico. Observa-se um aumento de coliformes na estação chuvosa, quando deveria ser o inverso. Isso ocorre devido ao fato dos esgotos nos distritos não serem canalizados diretamente às drenagens e sim despejados nas imediações das moradias, permitindo o aumento da concentração na estação chuvosa pelo carreamento dos dejetos pela água de escoamento superficial (Neves, 2005).

\section{GEOQUÍMICA DOS SOLOS}

Na bacia ocorrem cinco tipos de solos (Fig. 2), além dos afloramentos rochosos (AR). Os latossolos são mais ricos, quantitativos e qualitativamente, em proporção e variedade de elementos químicos. O Latossolo Amarelo Vermelho típico-LAVw, solo residual nos diques de rochas metabásicas, apresenta teores variados de cromo (147ppm), cobre $(175,159$ e $147 \mathrm{ppm})$, chumbo (57ppm), zinco (140 e 104ppm), vanádio (347 e 403ppm), bário (226ppm). Somente nesse tipo de solo foi detectada a presença de elementos como lantânio, cobalto e berílio. O teor em ferro varia entre 10 e $15 \%$ e o alumínio, entre $0,12 \%$ e $2,6 \%$. Os valores médios obtidos para o magnésio, potássio e fósforo foram, respectivamente, $0,01 \%, 0,02 \%$ e 0,04\%. O Latossolo Ácrico típico (LVw) e o Latossolo Vermelho Acriférrico típico (LVwf) apresentam um decréscimo nos teores de $\mathrm{Cu}$ (12 e 27ppm), $\mathrm{Cr}$ (67 e 94ppm), Zn (2,7ppm), V (0,08 e 0,13ppm), Ba (1,9 e $2,6 \mathrm{ppm}$ ), devido à filiação com rochas ferruginosas do grupo Guinda (filito hematítico e quartzitos da formação Sopa Brumadinho e São João da Chapada). O Latossolo Vermelho Acriférrico típico (LVwf), tendo como 


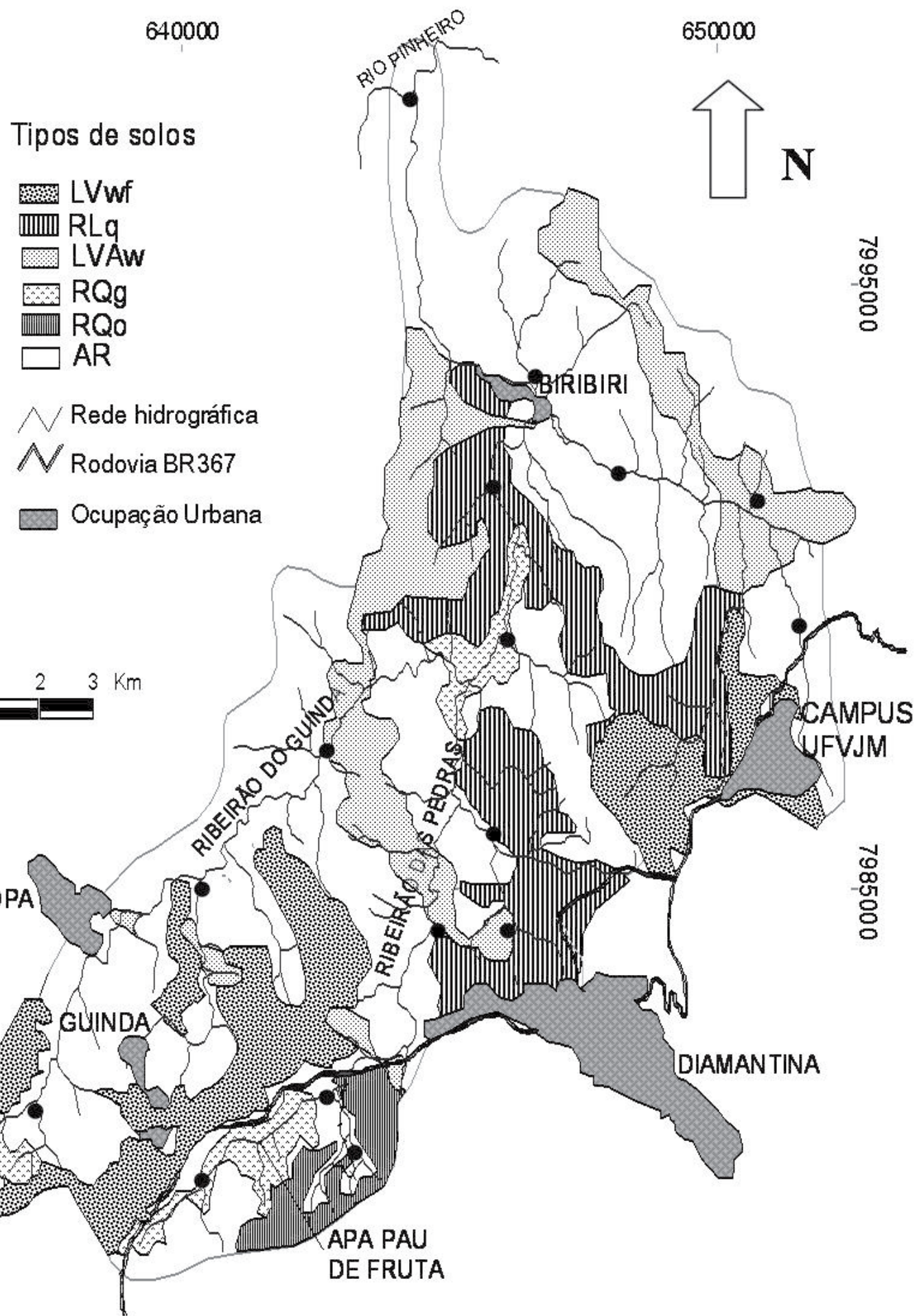

SIGLAS:

LVwf - LATOSSOLO VERM.ACRIFÉRRICO

- Pontos de monitoramento

RLq - NEOSSOLO LITÓLICO

LVAW - LATOSSOLO AMARELO VERMELHO de água

ROg - NEOSSOLO QUARZOARÊNICO HIDROMÓRFICO

RQQ - NEOSSOLO QUARTZOARÊNICO ÓRTICO

AR- AFLORAMENTO ROCHOSO

Figura 2: Mapas de distribuição dos solos na bacia hidrográfica do Ribeirão das Pedras (modificado de Neves, 2005). 
substrato rochoso o filito hematítico, apresentou teor em ferro $>15 \%$, além de valores de chumbo (68ppm), cádmio (4,8 e 20ppm) e arsênio (6ppm). Ao que parece alguns teores são de ocorrência natural, enquanto outros são associados às contaminações antrópicas. Os neossolos são naturalmente empobrecidos, entretanto se destacaram por apresentarem teores naturais de arsênio (5 e 8ppm) e lítio (5,2ppm) ambos ocorrentes com implicações geológicas e climáticas, um relacionado à ocorrência aurífera e o outro a vigência de clima semi-árido a árido em períodos geológicos passados. Nos Organossolos (Oys), associados aos Neossolos Hidromórficos (RQg), foram detectadas complexações de metais como: bário (111ppm), chumbo (12ppm), ítrio (8,8ppm), estrôncio (3ppm) e zinco (2,8ppm). Os sedimentos de corrente que mostraram alterações no conteúdo de metais, em geral, foram relacionados com interferência antrópica no sistema. Casos como sedimentos no leito da barragem da Perpétua (COPASA, distrito de Sopa) que apresentaram teores de chumbo (39ppm), arsênio (9ppm), cádmio (2,2ppm) são claramente devidos à influência da atividade garimpeira a montante. A contaminação seria principalmente por erosão dos solos, proporcionando uma abertura maior do sistema geoquímico natural como para o arsênio e parte do chumbo. Alguma contribuição externa não pode ser descartada, uma vez que, mesmo seguindo a normas ambientais (utilização de bacias de decantação, caixa de contenção de óleos) podem ocorrer vazamentos de combustíveis e resíduos sólidos em disposição inadequada, o que contribui, no caso, com parte do chumbo e a maioria do cádmio detectado (Neves, 2005).

\section{CONCLUSÕES}

A partir da análise geoquímica integrada dos componentes do sistema hidrográfico (solo, água e sedimento de corrente), constatou-se a influência direta do substrato geológico servindo como fonte de elementos químicos primários para o sistema. $\mathrm{O}$ processo de dissecação da paisagem e a atividade antrópica nas margens e cabeceiras influenciam na distribuição e concentração de alguns elementos químicos no solo e na água. $\mathrm{O}$ conteúdo geoquímico dos solos apresentou localmente ocorrências naturais anômalas de elementos como: $\mathrm{As}, \mathrm{Zn}, \mathrm{Pb} \mathrm{Cu}, \mathrm{Cr}, \mathrm{Cd}$, relacionados à mineralogia das rochas e processos pedogenéticos. Os sedimentos de corrente refletem o substrato e agregam elementos introduzidos no sistema por ação antrópica. Foram detectadas contaminações pontuais de $\mathrm{Cd}, \mathrm{Pb}, \mathrm{Hg}$, relacionados à atuação constante de garimpos. Constatou-se também que o clima influencia na disponibilidade dos elementos, i. e., em períodos chuvosos devido às altas taxas de lixiviação, e com o aumento da turbidez das águas tem-se um aumento proporcional com relação aos teores de metais pesados, especialmente de ferro e alumínio. Metais como cádmio e chumbo também são disponibilizados nesse período devido à redução do pH nas águas e podem alcançar concentrações acima dos limites estabelecidos. Estas superfícies quando recobertas por canga laterítica também atuam como área fonte de metais pesados para a sub-bacia, servindo de aporte sedimentar rico em ferro e metais associados. A falta de recuperação das áreas degradadas pelo garimpo, a urbanização desordenada, a falta de saneamento básico para os distritos de Sopa e Guinda e a demora na implantação efetiva do Parque do Biribiri são os principais fatores agravantes da qualidade ambiental na sub-bacia do Ribeirão das Pedras.

Agradecimentos: Capes (bolsa de doutorado - 2002 a 2005), IGC/UFMG, FCA/UFVJM, COPASA e IEF/ MG (colaboradores do projeto).

\section{REFERÊNCIA BIBLOIGRÁFICA}

Almeida-Abreu, P.A. 1993.A evolução geodinâmica da Serra do Espinhaço Meridional, Minas Gerais, Brasil. Tese de doutoramento. Albert-Ludwigs-Universität, Freiburg, Alemanha. 150p.

COPAM Comissão de Política Ambiental. 1986. Deliberação Normativa $\mathrm{n}^{\circ} 010$ de 16 de dezembro de 1986. Belo Horizonte, MG.

CONAMA Conselho Nacional do Meio Ambiente. 1986. Resolução CONAMA n 020 de 18 de junho de 1986. Brasília, D.F.

CONAMA Conselho Nacional do Meio Ambiente. 2005. Resolução CONAMA n 357 de 17 de março de 2005. Brasília, D.F.

Neves, S. C. 2005. Caracterização geoquímica ambiental das águas, solos e sedimentos de corrente da Bacia do Ribeirão das Pedras, Diamantina. MG. Tese de Doutoramento. Instituto de Geociências, Universidade Federal de Minas Gerais, Belo Horizonte. 174p. 